\title{
Leis em (com) nomes de vítimas: a ampliação do Estado polícia e a produção de subjetividades na contemporaneidade
}

\section{Laws in (with) name of victims: the enlargement of the police state and the production of subjectivities in the contemporaneity}

\section{Las leyes en favor (con el nombre) de las víctimas: la expansión del estado de policía y la producción de subjetividades en la contemporánea}

\author{
Analicia Martins de Sousa* \\ Universidade Federal do Rio de Janeiro - UFRJ, Rio de Janeiro, Brasil
}

\begin{abstract}
RESUMO
Nos últimos anos, um conjunto de acontecimentos veiculados pela mídia nacional vem conferindo certo destaque à figura das vítimas. Um dos resultados disso, no país, tem sido a elaboração e aprovação de leis federais em prol das vítimas e, ainda, outras designadas com o nome destas. Diante disso, objetivou-se investigar o nexo entre eventos com vítimas que tiveram extensa repercussão na mídia e a elaboração de leis que as homenageiam no Brasil. Para tanto, foram examinadas, a partir da abordagem teóricometodológica de Michel Foucault, as justificativas de propostas de leis que tramitam na Câmara Federal dos Deputados e de outras já promulgadas que receberam o nome de vítimas. Constatou-se que a valorização e a projeção destas últimas no contexto nacional tornaram-se formas de ampliação dos alcances do Estado polícia, traduzidas por vezes no recrudescimento da legislação penal. Aliado a isso, contribuem para a produção de subjetividades que se percebem como vítimas, identificando-se com as que são homenageadas por leis e, assim, clamam pela proteção estatal.
\end{abstract}

Palavras chaves: leis, vítimas, punição, Estado polícia.

\section{ABSTRACT}

In the last years, a series of events conveyed by the national media has given a certain prominence to the victims. One of the results of this in the country has been the elaboration and approval of federal laws in favor of the victims and others named after them. Taking this into consideration, the objective was to investigate the nexus between events with victims that had extensive repercussion in the media and the elaboration of laws that honor them in Brazil. In order to do so, Michel Foucault's theoreticalmethodological approach was examined to justify proposals for laws in the Federal Chamber of Deputies and others already enacted that were named victims. It was noted that the valorization and projection of the latter in the national context have become forms of expansion of the scope of the police 
state, sometimes translated into the intensification of criminal law. Besides, they contribute to the production of subjectivities that perceive themselves as victims, identifying themselves with those who are honored by laws and, thus, cry for state protection.

Keywords: laws, victims, punishment, State police.

\section{RESUMEN}

En los últimos años, una serie de eventos difundidos por los medios de comunicación nacionales está dando un poco de protagonismo a la figura de las víctimas. Uno de los resultados, en el país, ha sido el desarrollo y la adopción de las leyes federales para las víctimas y otros designados con el nombre de éstos. Delante de eso, el objetivo fue investigar la relación entre los eventos con víctimas que tuvieron una amplia cobertura de los medios de comunicación y la elaboración de leyes que hacen honor en Brasil. Por lo tanto, se examinaron, desde el enfoque teórico y metodológico de Michel Foucault, las leyes de justificaciones propuestas presentadas en la Cámara de Representantes Federal y otros ya realizada que fueron nombrados víctimas. Se encontró que la recuperación y la proyección de este último en el contexto nacional se han convertido en la forma de ampliar los alcances de lo estado de policía, traducido a veces en el resurgimiento de la ley penal. Junto a esto, contribuir a la producción de subjetividades que se perciben como víctimas, identificándose con los homenajeados por leyes y por lo tanto pedir la protección del Estado.

Palabras clave: leyes, víctimas, castigo, Estado policía.

\section{I ntrodução}

Nos últimos anos, um conjunto de acontecimentos veiculados pela mídia nacional vem conferindo certo destaque à figura da vítima. Comumente, trata-se de situações envolvendo violência (urbana, doméstica, sexual, no trânsito, da natureza, dentre outras designações), nas quais se chama a atenção para o sofrimento causado às vítimas e aos seus familiares. A indignação social diante do ocorrido se expressa com frequência em demandas por justiça, ou na expectativa de que "seja feita justiça". Em certas ocasiões, prepondera ainda a concepção de que o sofrimento da vítima poderia ter sido evitado, ou que a violência e os danos provocados a ela seriam resultados de uma legislação leniente, justificando, deste modo, a criação de leis mais rigorosas, ou ainda, o agravamento da legislação penal no Brasil.

Provavelmente, um dos resultados da projeção da vítima sofredora no País tem sido a elaboração de Projetos de Lei (PLs), bem como a promulgação de leis federais em seu nome, ou ainda, batizados com o seu nome, como é o caso, por exemplo, da conhecida Lei Maria da Penha (Lei 11.340/06) que dispõe sobre violência doméstica e da Lei Joana Maranhão (Lei 12.650/12) que modifica regras relativas à prescrição de crimes contra crianças e adolescentes. Ao que parece, 0 legislador nacional segue uma tendência identificada em países como os Estados Unidos, onde episódios envolvendo vítimas de crimes, com 
grande destaque nos meios de comunicação de massa, motivaram a criação de leis punitivas que foram batizadas com o nome daquelas. Nessa vertente, o presente estudo objetivou investigar o nexo entre eventos com vítimas que tiveram extensa repercussão na mídia e a elaboração de leis que as homenageiam no Brasil. Para tanto, foram examinadas as justificativas de propostas de leis que tramitam na Câmara Federal dos Deputados e de outras já promulgadas, batizadas com o nome de vítimas. A hipótese foi a de que a projeção da vítima e a indignação social, promovidas pela mídia diante de episódios associados à noção de violência, têm dado incremento ao Estado polícia, ao mesmo tempo que fazem funcionar processos de subjetivação nos quais um número cada vez maior de pessoas se reconhece como vítima.

\section{Na causa das vítimas}

A intensa divulgação feita pelos meios de comunicação de massa sobre eventos envolvendo vítimas da violência, a exibição do seu sofrimento, a indignação social, as reivindicações por Justiça, dentre outros aspectos, podem ser apreendidos atualmente como importantes fatores na mobilização da opinião pública e na criação de campanhas, políticas e leis voltadas à causa das vítimas. Como reflete Garland (2008, p. 265), com essa "política das vítimas", aplicada desde as últimas décadas do século XX nos EUA, os interesses de vítimas de crimes e dos movimentos organizados em seu nome vêm tomando o lugar do interesse público. Dito de outro modo, para que o cidadão tenha seus direitos reconhecidos $\mathrm{e}$ respeitados ele deve ser caracterizado como vítima inocente e sofredora, ou, em uma expressão, como cidadão-vítima. Com isso, continua aquele autor, as vítimas se tornaram uma espécie de grupo favorecido, ao qual se dirigem discursos políticos, agências do governo e da justiça criminal, por exemplo.

Nesse sentido, tem sido fundamental o papel desempenhado pela mídia na projeção da figura da vítima, pois a indignação gerada por determinadas notícias vai influenciar diretamente o modo como a violência e o crime são percebidos na sociedade e a forma de reação a eles. Como expõe Cerruti (2009), a comunicação emocional produz processos de identificação ou de emoção compartilhada que, por sua vez, gera uma consciência coletiva de vingança sobre o crime. Aliado a isso, também ganha vulto atualmente a crença de que o sofrimento das vítimas é causado por uma legislação leniente. Assim, o crime vai ser definido não pela transgressão ou desvio em relação à norma, mas pelo fato de haver vítimas. Em outros termos, o crime passa a ser definido por sua dimensão emocional, a qual se mescla com elementos de racionalidade e vingança. Nessa vertente, Salas (2010, 
p. 17, tradução nossa) afirma que hoje "a pena não é mais entendida como uma sanção por má conduta, mas como uma reparação de injustiças".

Não são raros, contudo, entendimentos diversos daquele citado acima que defendem a lei como reparação às injustiças - injustiças estas que dizem respeito menos a questões relativas à pobreza e à desigualdade social, por exemplo, do que ao padecimento das vítimas inocentes. Nesse rumo, no âmbito da Justiça, tornam-se cada vez mais comuns, em situações com vítimas, reparações de ordem financeira que têm como objetivo compensar o indivíduo pelo dano sofrido (Bauman, 2009).

Porém, importa refletir se a pretensa objetividade de uma lei ou de uma sentença judicial poderá sanar as demandas subjetivas, por vezes marcadas por sentimentos de indignação, revolta e desejo de vingança, de pessoas que sofreram violência ou tiveram um ente querido assassinado brutalmente, por exemplo. Como ilustra Garland (2008), nos Estados Unidos, os parentes de vítimas de crimes que assistiram pessoalmente a execução dos assassinos relataram posteriormente sua insatisfação com a sentença judicial - a morte do assassino não foi suficiente, para eles. Portanto, é fundamental indagar sobre as respostas que vêm sendo dadas pelo Estado diante de crimes - particularmente aqueles de grande repercussão na mídia. Crer no encarceramento e na suposta ressocialização dos que hoje são caracterizados como agressores é, de fato, desconhecer a realidade do sistema penitenciário brasileiro (Karan, 1996; Malaguti Batista, 2009). Considerando que as leis são ficções, são produções humanas, é preciso se pensar em outras que criem alternativas à racionalidade punitiva que goza da adesão e da simpatia de grande parte das pessoas.

A hipótese do presente estudo aponta para certo funcionamento do Estado no novo capital mundial, atuando intimamente interligado ao sistema penal (Wacquant, 2012). Dito de outro modo, como no neoliberalismo o Estado perde o lugar de mediador das relações sociais (como ocorria no chamado Estado de bem-estar social), resta a ele atuar na segurança dos indivíduos (Birman, 2005), ou ainda, das vítimas virtuais.

Aliado a isso, como reflete Malaguti Batista (2011), no atual estágio de desenvolvimento do capital mundial existe uma estreita relação entre o Estado polícia e a mídia, fortalecida por meio da produção do medo e das demandas por mais penas, mais vigilância, mais controle etc. Também nesse viés, Coimbra e Scheinvar (2012) avaliam que os meios de comunicação de massa estimulam cotidianamente a produção de subjetividades punitivo-penais, as quais são alimentadas pela fé inquebrantável na pena como recurso à insegurança que aflige as sociedades neoliberais. 
Importa considerar também que a criação de leis como a conhecida Lei Maria da Penha que faz uma opção retributivista-aflitiva, ainda que acione necessárias medidas de proteção às mulheres agredidas, contribui para o grande encarceramento em curso (Batista, 2007). A análise crítica sobre a elaboração de determinadas leis na atualidade, portanto, não deve ignorar suas prováveis interseções com o projeto político-econômico das sociedades neoliberais.

Também nesse rumo, cabe mencionar que as penalidades aplicadas nos casos de violência ou de crimes não estão desvinculadas da condição socioeconômica e étnica dos supostos culpados, ou seja, não há mudanças quanto à seletividade do sistema penal. Embora isso não seja algo inerente às leis criadas atualmente em (com) nome de vítimas, é preciso considerar seus prováveis efeitos, uma vez que podem fomentar outras formas de violência, como sinalizado anteriormente. Não é demais afirmar que podem ainda contribuir para a multiplicação de mecanismos de segurança que hoje se integram, sob diferentes modalidades, ao funcionamento das sociedades neoliberais (Foucault, 2008), nas quais os processos de criminalização alcançam um número cada vez maior de pessoas.

\section{Método}

A hipótese básica do presente estudo foi a de que a repercussão midiática de episódios envolvendo vítimas da violência tem estimulado a elaboração e a promulgação de leis de cunho punitivo feitas em (com) nome daquelas. Com isso, alguns PLs em tramitação na Câmara Federal dos Deputados, assim como outros já promulgados como leis, formaram o material empírico examinado. Essa opção metodológica ocorreu devido ao fato de que em tais documentos encontram-se os argumentos do legislador que fundamentam a criação das referidas leis no país.

\section{Procedimentos}

Para a concretização da pesquisa, foi feita busca na internet sobre menções a leis e iniciativas de leis nacionais que foram batizadas com o nome de vítimas. Nos sites Folha de São Paulo, O Estado de São Paulo, O Globo, G1 - Portal de Notícias da Globo, Uol Notícias e Aracatu Online foram encontradas referências a seis documentos legislativos, todos diretamente associados a situações que alcançaram grande repercussão na mídia. Em sequência, no Portal da Câmara Federal dos Deputados na internet ${ }^{1}$, teve-se acesso ao texto integral desses documentos, os quais se encontram organizados na Tabela 1. 
Tabela 1

Documentos legislativos selecionados para análise

\begin{tabular}{|c|c|c|c|c|}
\hline $\mathrm{n}^{\circ}$ do $\mathrm{PL}$ & Data & Antor & Caput & Nome da lei \\
\hline 4559 & $\begin{array}{c}03 \text { de } \\
\text { Dezembro } \\
\text { de } 2004\end{array}$ & $\begin{array}{c}\text { Poder } \\
\text { Executivo }\end{array}$ & $\begin{array}{l}\text { Cria mecanismos para coibir a } \\
\text { violência doméstica e familiar } \\
\text { contra a mulher, nos termos } \\
\text { do } \S 8^{\circ} \text { do art. } 226 \mathrm{da} \\
\text { Constituiçăo Federal, e dá } \\
\text { outras providências. }\end{array}$ & $\begin{array}{l}\text { Lei Maria da Penha } \\
\text { (Lei } 11.340 \text {, de } 07 \text { de } \\
\text { agosto de 2006) }\end{array}$ \\
\hline 6719 & $\begin{array}{c}23 \text { de } \\
\text { Dezembro } \\
\text { de } 2009\end{array}$ & $\begin{array}{l}\text { Senado Federal - } \\
\text { CPI da Pedofilia }\end{array}$ & $\begin{array}{l}\text { Altera o Decreto-Lei n }{ }^{\circ} 2.848 \text {, } \\
\text { de } 7 \text { de dezembro de } 1940 \\
\text { (Código Penal), com a } \\
\text { finalidade de modificar as } \\
\text { regras relativas à prescriçăo } \\
\text { dos crimes praticados contra } \\
\text { crianças e adolescentes. }\end{array}$ & $\begin{array}{l}\text { Lei Joana Maranhão } \\
\text { (Lei } 12.650 \text {, de } 17 \text { de } \\
\text { maio de 2012) }\end{array}$ \\
\hline 7672 & $\begin{array}{l}16 \text { de } \\
\text { Julho de } \\
2010\end{array}$ & $\begin{array}{l}\text { Poder } \\
\text { Executivo }\end{array}$ & $\begin{array}{l}\text { Altera a Lei no } 8.069 \text {, de } 13 \\
\text { de julho de } 1990 \text {, que dispóe } \\
\text { sobre o Estatuto da Criança e } \\
\text { do Adolescente, para } \\
\text { estabelecer o direito da criança } \\
\text { e do adolescente de serem } \\
\text { educados e cuidados sem o } \\
\text { uso de castigos corporais ou } \\
\text { de tratamento cruel ou } \\
\text { degradante. }\end{array}$ & $\begin{array}{l}\text { Lei Menino Bernardo } \\
\text { (Lei 13.010, de } 26 \\
\text { Junho de 2014) }\end{array}$ \\
\hline 2793 & $\begin{array}{c}29 \text { de } \\
\text { Novembro } \\
\text { de } 2011\end{array}$ & $\begin{array}{l}\text { Paulo Teixeira (PT/SP), } \\
\text { Luiza Erundina (PSB/SP), } \\
\text { Manuela D'Ávila } \\
\text { (PCdoB/RS), } \\
\text { João Arruda (PMDB/PR), } \\
\text { Brizola Neto (PDT/RJ), } \\
\text { Emiliano José (PT/BA) }\end{array}$ & $\begin{array}{l}\text { Dispōe sobre a tipificação } \\
\text { criminal de delitos } \\
\text { informáticos e dá outras } \\
\text { providências. }\end{array}$ & $\begin{array}{l}\text { Lei Carolina } \\
\text { Dieckmann (Lei } \\
12.737 \text {, de } 30 \mathrm{de} \\
\text { novembro de 2012) }\end{array}$ \\
\hline 7544 & $\begin{array}{l}13 \text { de Maio } \\
\text { de } 2014\end{array}$ & Ricardo Izar (PSD/SP) & $\begin{array}{l}\text { Altera o Decreto-Lei } n^{\circ} 2.848 \text {, } \\
\text { de } 07 \text { de dezembro de } 1940 \text { - } \\
\text { Código Penal - para instituir o } \\
\text { crime de incitaçăo virtual ao } \\
\text { crime. }\end{array}$ & $\begin{array}{l}\text { Lei Fabiane } \\
\text { Maria de Jesus } \\
\text { (em tramitaçăo) }\end{array}$ \\
\hline 2237 & $\begin{array}{l}27 \text { de } \\
\text { Julho de } \\
2015\end{array}$ & Cesar Halum (PRB/TO) & $\begin{array}{l}\text { Altera o artigo } 212 \text {, criando o } \\
\text { parágrafo único, do Decreto- } \\
\text { lei n }{ }^{\circ} 2.848 \text {, de } 07 \text { de } \\
\text { dezembro de } 1940 \text { - Código } \\
\text { Penal - Lei Cristiano Araújo. }\end{array}$ & $\begin{array}{l}\text { Lei Cristiano Araújo } \\
\text { (em tramitaçăo) }\end{array}$ \\
\hline
\end{tabular}

Seguindo as datas em que as propostas de leis foram encaminhadas à Câmara Federal dos Deputados, destaca-se inicialmente o PL 4559/04, que deu origem à Lei 11.340/06, conhecida como Lei Maria da Penha (LMP) que, dentre outros aspectos, cria mecanismos para coibir a violência doméstica e familiar contra a mulher e altera o Código Penal (Lei 2.848/40). Aquela lei foi assim nomeada em homenagem à Maria da Penha Maia Fernandes que sofrera violência por parte do marido durante anos. O caso chegou à Comissão Interamericana dos Direitos Humanos, órgão da Organização dos 
Estados Americanos (OEA), com sede em Washington, Estados Unidos. Essa Comissão condenou o Brasil por negligência e omissão quanto à violência doméstica e recomendou que fosse criada, no país, legislação adequada ao assunto.

Em sequência, o PL 6719/09 ${ }^{2}$ foi sancionado como Lei 12.650/12, também chamada de Lei Joana Maranhão (LJM), que altera o Código Penal quanto às regras de prescrição de crimes de abuso praticados contra crianças e adolescentes. Na regra anterior, o prazo de prescrição começava contar logo após o crime, pela nova regra, a partir dos 18 anos completos da pessoa vitimada. O nome da lei homenageia a nadadora que revelou em 2008 ter sofrido abuso sexual aos nove anos de idade por um ex-técnico. Contudo, ela não pôde processá-lo porque, aos 21 anos, quando fez a revelação do abuso, o crime havia prescrito. Durante o período de tramitação da iniciativa de lei, o caso da atleta foi lembrado em matérias de jornais e também por políticos como exemplo da pertinência de revisão da legislação nacional. Por sugestão do relator da proposta, ela foi batizada com o nome da atleta, que acompanhou pessoalmente a votação na Comissão de Constituição e Justiça no Senado (Vasconcelos \& Brigido, 2009).

O terceiro documento listado é o PL7672, encaminhado à Câmara Federal em 2010. Conhecido como "Lei da Palmada", o PL altera o Estatuto da Criança e do Adolescente (Lei 8069/90) visando proibir castigos corporais contra menores de idade. A proposta foi iniciativa de um grupo de organizações não governamentais (ONGs) e entidades de defesa dos direitos das crianças (Guimarães, 2010). Em 2014, depois de quatro anos de tramitação, o PL7672/2010 foi aprovado no Senado. Na ocasião, ganhou o nome de Lei Menino Bernardo (LMB) em homenagem a Bernardo Boldrini que, em abril daquele ano, teria sido morto pela madrasta e uma amiga dela no interior do Rio Grande do Sul, com o suposto apoio do pai (Guerreiro, 2014). A proposta foi sancionada em 27 de junho de 2014, como Lei 13.010, pela então Presidente da República Dilma Rousseff.

A quarta proposição legislativa selecionada é o PL 2793 de 2011, que altera o Código Penal com vistas à tipificação penal de crimes informáticos. O PL ficou conhecido posteriormente como Lei Carolina Dieckmann (LCD). Embora seja o único $\mathrm{PL}$, dentre os revisados, em que não há referência à violência, os meios de comunicação chamaram atenção para o drama e o sofrimento vivido pela vítima, uma atriz da Rede Globo que, em 04 de maio de 2012, teve fotos nuas vazadas na internet. No dia 14 de maio, ela deu entrevistada ao Jornal Nacional relatando o seu sofrimento diante do ocorrido (G1, 2012 , s/p). No dia seguinte, em 15 de maio, o referido PL foi votado no plenário da Câmara. Durante a votação, o episódio envolvendo a atriz foi lembrado por um dos parlamentares que defendia a aprovação do Projeto (Decat, 2012). Em novembro do mesmo ano, a 
proposta foi sancionada como Lei $12.737 / 12$ pela Presidente da República Dilma Rousseff.

O PL 7544/14, quinto documento escolhido, dispõe sobre o crime de incitação virtual ao crime. O Projeto foi apresentado no dia 13 de maio de 2014, dez dias após o espancamento e morte da dona de casa Fabiane Maria de Jesus por moradores do Guarujá, litoral de São Paulo. O fato teria ocorrido a partir de boato gerado por página no Facebook, na qual uma mulher parecida com Fabiane era apontada como responsável pelo sequestro de crianças. Após a morte da dona de casa, o advogado da família mencionou em entrevista a possibilidade de o deputado federal Ricardo Izar (PSD/SP) propor a Lei Fabiane de Jesus (LFJ). Além disso, comparou a iniciativa com a Lei Maria da Penha, a qual, em suas palavras, "[...] foi criada por causa de uma mulher que foi espancada pelo marido, o que é muito grave. Só que esse caso da Fabiane é pior ainda, pois além de ser inocente, ela foi espancada até a morte" (Martins, 2014, s/p).

A sexta proposta selecionada é o PL 2237/15, nomeada como Lei Cristiano Araújo (LCA) em homenagem ao cantor sertanejo, morto em 24 de junho de 2015, em um acidente de carro. Em relação ao episódio, chama atenção o número de propostas de leis e a rapidez com que foram apresentadas à Câmara. No dia 25 de junho, um dia após o acidente, foi apresentado o PL 2103/2015 que visava tornar obrigatório o alerta sonoro e visual para o uso do cinto de segurança (Aracatu Online, 2015), com base no fato de que o cantor Cristiano Araújo não utilizava o equipamento no momento do acidente. Após a divulgação na internet de fotos do artista morto, foi a vez do PL 2199/2015 e do PL 2175/2015, em 01 de julho; do PL 2237/2015 (Lei Cristiano Araújo), em 27 de julho; e do PL 2774/2015, em 26 de agosto. Esses quatro últimos Projetos propunham criminalizar 0 vilipendio de cadáver, alterando, com isso, o Código Penal. Para análise no presente estudo, optou-se pelo PL 2237/15, uma vez que em seu caput é referido como Lei Cristiano Araújo.

Nos documentos selecionados, listados na Tabela 1, foi priorizado 0 exame dos argumentos que justificam a criação de novas leis federais em (com) nome de vítimas. Foi feita análise de discurso com base na abordagem teórico-metodológica de Michel Foucault (1995), por meio da qual é possível vislumbrar os jogos discursivos que envolvem a figura da vítima e, ao mesmo tempo, acionam processos de subjetivação nos quais as pessoas se identificam com esta e clamam por Justiça contra seus ofensores. 


\section{Resultados e Discussão}

Por se tratar de uma pesquisa de cunho qualitativo, no presente estudo, não se intentou fazer generalizações sobre a elaboração de leis no Brasil, quiçá em outros países, mas colocar em análise certa produção discursiva, da qual toma parte iniciativas de leis nacionais feitas em (com) nome de vítimas.

Importa assinalar que o lugar de destaque conferido às vítimas na contemporaneidade vem sendo discutido por vários estudiosos (Eliacheff \& Larivière, 2007). No presente estudo, a valorização de tais figuras é percebida a partir de um aspecto semelhante entre 0 Brasil e outros países, a criação e/ou alteração de leis voltadas às vítimas. No contexto nacional, embora se encontre leis que foram produzidas/modificadas a partir de episódios que tiveram grande destaque na mídia nacional ${ }^{3}$, nota-se que elas não foram batizadas ou tornaram-se conhecidas com o nome de uma vítima. Essa novidade na legislação nacional é identificada especialmente a partir do ano de 2006, quando foi sancionada a Lei Maria da Penha (Lei 11.340/06), que parece ter se tornado uma fonte inspiradora de outras leis que homenageiam vítimas.

\section{Mulheres e crianças vítimas}

Em uma primeira visada sobre os documentos selecionados, desperta atenção o fato de que a maioria deles, com exceção da Lei Menino Bernardo, propõe a alteração de artigos e parágrafos do Código Penal brasileiro, criando, dentre outros aspectos, novos tipos penais. Porém, pode-se dizer que todos os documentos examinados são de cunho punitivo, uma vez que a lei citada inicialmente também prevê sanções a pais e outros responsáveis que "utilizarem castigo físico ou tratamento cruel ou degradante como formas de correção, disciplina, educação $[\ldots]^{\prime \prime}(\mathrm{s} / \mathrm{p})$. Esse dado vai ao encontro da reflexão de Batista (2011) de que, a fé na pena como forma de resolução dos conflitos sociais e de dissuasão de novos delitos se mantém a despeito da ausência de dados empíricos que comprovem sua efetividade nesse sentido. Ou seja, mais leis penais, mais prisões, mais punições não têm se revertido na diminuição da violência ou de crimes na sociedade. Isso pode ser confirmado pelos dados apresentados no Anuário Brasileiro de Segurança Pública (Fórum Brasileiro de Segurança Pública, 2015), segundo o qual, nos últimos 20 anos houve um aumento vertiginoso do número de pessoas encarceradas no Brasil, porém isso não resultou na redução de crimes na sociedade.

Diante disso, a questão que se coloca é: o que se quer com a criação de novas leis, como as que são listadas no presente estudo? Talvez, 
como sintetiza Montenegro (2015), se almeje simplesmente acalmar eleitores, dando-Ihes a impressão de que algo está sendo feito para combater situações indesejadas, ainda que por meio de leis previsivelmente ineficazes. Talvez, um dos grandes desafios nas questões que envolvem violência/vítima seja pensar alternativas à pena, para lembrar o pensamento de Baratta (2002). Nesse sentido, vale citar como exemplo trabalhos com grupos reflexivos, voltados a temática violência doméstica, que romperam com uma visão dicotômica e reducionista que caracteriza homens como algozes e mulheres como vítimas (Beiras, Moraes, Alencar-Rodrigues \& Cantera 2012).

Não obstante a existência, no Brasil, de experiências como aquela citada acima, parece vigorar certo senso comum punitivo que se aproxima do modelo norte-americano, no qual, como reflete Garland (2008), leis são produzidas como respostas instantâneas a crimes graves, em uma espécie de alívio e gratificação, tornando-se, de fato, um gesto de retaliação com o objetivo de reconfortar o público que clama por segurança. Nesse sentido, o estudioso cita como exemplo leis que foram batizadas nos EUA (Lei Megan, Lei de Jenne, Lei de Stephanie etc.) e na Grã- Bretanha (Lei de Sarah) com o nome de vítimas de crimes.

Na revisão das iniciativas de leis nacionais, chama a atenção que, em três delas (Lei Maria da Penha, Lei Joana Maranhão e Lei Menino Bernardo), movimentos sociais e ONGs estiveram mobilizados em sua aprovação. Esse dado concorda com a literatura revisada, segundo qual, as demandas por penas ou leis mais severas vêm sendo encampadas por movimentos organizados em torno das vítimas na atualidade (Garland, 2008; Cerruti, 2009).A menção aos direitos humanos aparece como mais um dado que aproxima os PLs examinados sobre violência contra mulheres e crianças.

[...] "a violência doméstica contra a mulher constitui uma das formas de violação dos direitos humanos, independente da penalidade aplicada". (LMP, s/p)

[...] incluímos como premissa de apresentação da proposição, portanto, a compatibilização do marco legal em vigor ao sistema internacional e nacional de proteção dos Direitos Humanos de crianças e adolescente [...]. (LMB, s/p).

Interessa assinalar que, nos anos 1980 , período da redemocratização do Brasil, muitos debates na sociedade giravam em torno da questão da violência e das arbitrariedades cometidas no interior das instituições do Estado; havia, diante disso, uma demanda por contenção do poder punitivo. Porém, desde a passagem para o século XXI, diversas situações e comportamentos identificados como formas 
de violência têm sido interpretados como desrespeito aos direitos humanos (Sousa, 2015). É certo que as leis mencionadas acima visam proteger mulheres e crianças contra a violência, criando medidas pertinentes nesse sentido. Contudo, apesar das boas intenções, hoje, sob o argumento de defesa dos direitos humanos se multiplicam demandas por penas contra aqueles que os teriam violado, intensificando, assim, o alcance do poder punitivo do Estado (Karan, 1996; Batista, 2011).

Embora, no atual contexto, certas bandeiras de movimentos sociais possam se alinhar ao Estado penal e suas políticas de segurança e penalização, como refletem Coimbra e Nascimento (2009), isso não significa que não há possibilidades de transformação e superação das formas de opressão nas sociedades de controle no capitalismo contemporâneo. Como defendem essas autoras, contra novas capturas e desalento, no Estado penal, os movimentos sociais devem entender o contexto histórico em que estão inseridos, colocando constantemente suas práticas em análise. Para tanto, é preciso que desnaturalizem conceitos e princípios que fazem parte de suas lutas, vendo-os como construções históricas datadas. Além disso, acrescenta-se, é fundamental a reflexão crítica e aprofundada acerca da fé que se deposita na penalização e, ao mesmo tempo, a afirmação de um compromisso radical com a liberdade.

Nos documentos revisados, verifica-se ainda que a indicação de modificação da normativa legal, incluindo a alteração do processo penal, especialmente no que tange à questão da violência no país, se fundamenta muitas vezes em tratados, convenções e diretrizes internacionais. O PL 4559/2004 (LMP), por exemplo, lembra que, a partir de denúncia do caso Maria da Penha à Comissão Interamericana de Direitos Humanos, foi recomendado ao Estado brasileiro, dentre outros fatores, [...] simplificar os procedimentos judiciais penais a fim de que possa ser reduzido o tempo processual, sem afetar os direitos e garantias do devido processo [...] (s/p).

Também nesse viés, o PL7672/10 (LMB) se respalda nas recomendações de organismos internacionais para a modificação de leis voltadas a infância no país:

O reconhecimento e a incorporação de marcos normativos direcionados à eliminação da violência contra crianças e adolescente representa ponto de preocupação e é, há alguns anos, objeto de pronunciamentos e de orientações de instâncias como a Comissão Interamericana de Direitos Humanos [...]. (LMB, s/p)

A influência de agências e organismos internacionais sobre problemáticas sociais no Brasil não é novidade. Importa chamar a atenção, todavia, para o fato de que, com base em argumentos 
humanitários e politicamente corretos, vêm sendo acionadas certas estratégias de governamentalidade (Foucault, 2008) que ganham a adesão e os aplausos de grande parte das pessoas. Em outros termos, uma espécie de política do bem, da proteção e da vigilância (contra criminosos, indesejáveis, perigosos, agressores, abusadores, etc.) põe em curso uma rede heterogênea de dispositivos de segurança e controle social (ONGs, projetos universitários, profissionais, avaliações psicológicas, tratamentos, resoluções, leis, etc.) que se estende por toda a sociedade.

Para o legislador, diante de dados e situações cotidianamente noticiados pela mídia, envolvendo violência contra mulheres e crianças no Brasil, parece óbvia a necessidade de aumento da penalização, seja para prevenir novos crimes seja para aplacar a sensação de impunidade. Todavia, não são levados em conta estudos conduzidos no país que questionam conceitos, dados e metodologia de pesquisa, utilizados por ONGs ou agências internacionais para fundamentar argumentos sobre a adoção de mais penas e/ou medidas punitivas no enfrentamento de problemas sociais (Sousa, 2015). O consenso em torno da penalização parece se alinhar a outro que se estabelece atualmente sobre a noção de violência, a qual abarca cada vez mais comportamentos, relações, conflitos, etc. 0 resultado disso pode ser a generalização ou banalização de situações identificadas como violência, ao mesmo tempo que outras, seriamente graves ou que divergem dos padrões estabelecidos (denúncia, acusação e punição do agressor, por exemplo), não recebem a atenção e a compreensão necessárias (Montenegro, 2015).

Cabe notar que reflexões críticas sobre as atuais demandas punitivas, por vezes, são rechaçadas sob a acusação de "reacionárias" ou "defensoras de agressores". Isso ocorre especialmente quando os supostos agentes da violência são colocados sob os refletores de TV, descritos como cruéis e, assim, condenados previamente pelo grande público que, desejoso de vingança, pede punições mais severas por parte da justiça (Casara, 2015).

Outro dado semelhante entre os documentos analisados é a quase ausência de menções à figura dos agressores, embora tenham como resultado final, é certo, sua punição. Esse dado encontra ressonância na avaliação de Garland (2008, p. 317), segundo o qual, a exaltação das vítimas, especialmente nas situações envolvendo crimes, tem contribuído para anular a preocupação com os criminosos. No caso dos documentos revisados no presente estudo, pode-se dizer que 0 interesse sobre estes últimos é estritamente o de puni-los. Esse aspecto converge com o entendimento de que hoje, diferentemente das sociedades disciplinares do passado, não é mais possível crer nas ilusões de ressocialização no sistema penal (Malaguti Batista, 2009). Além disso, considerando o modo como são descritos no presente os 
agressores ou criminosos, parece se constituir uma visão maniqueísta que divide os indivíduos entre bons e maus, ou ainda entre vítimas inocentes e agressores malvados ( Vaz, 2010). Com isso, ao mesmo tempo que, impede-se a implicação subjetiva do sujeito que sofrera o agravo (Kehl, 2015), fixa-se o outro na categoria de agressor ou de sociopata, para usar um termo bastante visado por certa perspectiva psiquiátrica na atualidade (Brasiliense, 2010). O PL 6719/09 (LJM, $\mathrm{s} / \mathrm{p}$ ), por exemplo, chama a atenção para a "crueldade e frieza com que os agentes [dos abusos sexuais] executam seus crimes".

Como se nota, a repercussão no campo social de situações envolvendo mulheres e crianças vítimas da violência têm dado oportunidade à aprovação de leis federais no País. Embora, a princípio, tratem-se de vítimas, oriundas especialmente da classe média urbana, percebe-se, na pesquisa realizada, que as iniciativas de leis não se restringem a tal segmento social, pois alcançam também pessoas comuns, pertencentes aos segmentos populares. Mais além, a política das vítimas parece se beneficiar das celebridades e de sua projeção midiática, como se verá no próximo item.

\section{Celebridades e anônimos vítimas}

A política das vítimas, ao mesmo tempo que alça desconhecidos ao patamar de símbolo na luta pela justiça, também se autopromove a partir de figuras públicas, ou melhor, das celebridades vitimadas. Nesse caso, como se nota no material examinado, as demandas por penas vêm produzindo respostas políticas imediatas, ainda sob o calor das emoções e dos holofotes da mídia.

Dentre os documentos legislativos revisados, dois deles, o PL 2793/11 (LCD) e o PL 2237/15 (LCA), envolvem celebridades vítimas. O primeiro, apresentado à Câmara Federal em 2011, se tornou conhecido do público em 2012, após episódio envolvendo a atriz Carolina Dieckman, quando passou a ser identificado nos meios de comunicação com o nome desta. Embora na justificativa que acompanha o PL não haja referência aquele fato, o mesmo foi mencionado em sessão da Câmara que, no dia seguinte à entrevista comovente dada pela atriz a uma rede de televisão em horário nobre, aprovou a nova lei, como citado anteriormente. Cabe mencionar que o referido PL passou à frente de um Projeto anterior, o PL 84 de 1999 sobre a tipificação de "[...] condutas realizadas mediante uso de sistema eletrônico [...]" (LCD, s/p), e da discussão sobre o Marco Civil da internet e o capítulo do Código Penal acerca dos crimes cibernéticos. Em que pesem contrariedades e dissensos envolvendo o texto da nova lei, não se pode negar que o apelo e a comoção 
gerados em torno do episódio envolvendo uma celebridade contribuíram para a sua rápida aprovação na Câmara Federal.

Em situações como a relatada acima, talvez seja mais adequado falar de certo oportunismo de políticos que, diante da comoção popular gerada em torno de figuras conhecidas na sociedade, vêem a chance de obter visibilidade, chamando atenção de seus eleitores, ainda que seja por meio de leis que passaram ao largo de efetivo debate social. Talvez isso fique ainda mais evidente no PL 2237/15, que envolve uma celebridade vítima de acidente fatal, o cantor sertanejo Cristiano Araújo, que posteriormente foi fotografado morto e as imagens disponibilizadas na internet. Esse Projeto de Lei e outros envolvendo o artista, citados anteriormente, foram encaminhados à Câmara Federal, dias após a sua morte, a qual alcançou repercussão surpreendente na mídia nacional, apesar de ele ser mais conhecido em certas regiões do país. O PL 2237/15 faz referência direta ao cantor sertanejo no texto de sua justificativa:

A presente proposta tem como inspiração o lamentável acontecimento que ocorreu com o cantor Cristiano Araujo, que teve seu procedimento de preparação do corpo, procedimento de embalsamamento, filmado e publicado nas redes sociais, aplicativos de celular e sites da internet. (LCA, s/p)

A rapidez com que propostas de leis como essa vêm sendo apresentadas à Câmara Federal, muitas vezes sob forte comoção popular e atenção da mídia, como já assinalado, talvez explique o modo como são fundamentadas e a ausência de debate social sobre o objeto que pretendem regular. Diante disso, concorda-se com Garland (2008) que, honrar a vítima por meio de uma lei vem se tornando uma estratégia política que pode dissimular diferentes interesses. Para o estudioso, há de fato um elemento de exploração da vítima, "na medida em que o nome do indivíduo é usado para evitar objeções às medidas que, na maioria das vezes, não passam de legislação retaliadora, aprovada unicamente para exibição pública e obtenção de vantagens políticas" (p. 317).

As questões apontadas nas propostas de leis citadas acima não se limitam às vítimas da classe média e às celebridades, como já sinalizado. Elas também são identificadas no PL 7544/14, batizado como Lei Fabiane Maria de Jesus, em homenagem a uma vítima proveniente das camadas populares, morta por espancamento. Mais uma vez, chama a atenção a rapidez com que a proposta foi apresentada à Câmara Federal, apenas alguns dias após a morte da dona de casa.

Ainda quanto ao PL7544/14 (LFMJ), este tem notadamente sua justificativa baseada no conteúdo de matérias de jornais da época 
sobre o espancamento e morte da dona de casa, assim como na avaliação pessoal do deputado autor do Projeto sobre o ocorrido:

O problema é que, nem todas as pessoas estão preparadas para analisar situações desagradáveis, difíceis, criminosas, ou ainda, não estão maduras o suficiente para filtrar o que pode ou não ser divulgado, compartilhado [...]. (LFMJ, s/p).

Embora as iniciativas de leis relacionadas neste item tenham sido elaboradas a partir de diferentes temáticas/vítimas, todas têm enfoque na punição, com proposta de alteração do Código Penal. O PL 2793/11, conhecido como Lei Carolina Dieckman, por exemplo, enfatiza em sua justificativa a necessidade de "criação de tipos penais específicos para o ambiente da Internet" (s/p).

Também nessa linha, o PL 2237/15, que foi batizado como Lei Cristiano Araújo, defende mais uma alteração no Código Penal, com vistas a criminalizar a divulgação de fotos de pessoas mortas, equiparando-a ao crime de vilipêndio de cadáver, já tipificado na legislação pátria:

[...] a conduta de divulgar imagem, vídeo ou outro material que contenha imagens ou cenas de cadáver ou parte dele não se encontra penalmente consolidada, pois muitas vezes só é punível quem coleta a imagem e não aquele que divulga a imagem. (LCA, s/p)

O PL 7544/14 (LFMJ), como já mencionado, pretende criminalizar a incitação virtual ao crime - modo como foi caracterizada a situação, ou mal entendido, que resultou na morte da dona de casa espancada. Para tanto, o PL assim descreve seu objetivo:

[...] coibir a prática da veiculação irresponsável de imagem, informação ou de qualquer outro conteúdo, seja ele verídico ou não, para que a população não tenha que acordar e ver nos noticiários casos como o da dona de casa Fabiane Maria de Jesus $[\ldots]$.

De um modo geral, as iniciativas de leis examinadas neste estudo têm como objetivo coibir ou punir condutas que poderão resultar em sofrimento no futuro. A ideia, ao que parece, é evitar o padecimento de vítimas virtuais, como se isso pudesse ser feito por meio da eliminação de prováveis falhas na legislação. Isso sugere que hoje passa a existir uma relação direta entre sofrimento e vontade, ou seja, alguém sofre por culpa do outro. Nesse caso, os fatores de ordem subjetiva, social, política e econômica, que poderiam intervir na questão, são provavelmente desconsiderados. Mais além, os PLs 
analisados dão a entender que as leis atuais não combatem o crime e a violência, precisando assim de novas para a resolução dos problemas sociais (Montenegro, 2015). Considerando que os regimes de verdade produzem conceitos, objetos e subjetividades (punitivopenais), pode-se dizer que, em realidade, as iniciativas de leis revisadas produzem novas ilegalidades, ao mesmo tempo que estabelecem formas de administrá-las (Foucault (2007).

\section{Considerações finais}

No Brasil, vem se tornando cada vez mais comuns leis que homenageiam vítimas, como uma provável forma de reconhecimento de seu sofrimento. Esse aspecto aponta para a importância que a figura da vítima adquiriu nas sociedades contemporâneas. Como se viu a partir do objetivo proposto neste estudo, são especialmente as situações que envolvem alguma forma de violência e, por conseguinte, vítimas, que recebem destaque na mídia, projetando, desse modo, estas últimas a símbolos da violência, da superação, da luta por direitos etc.

Como se notou ainda, a valorização e a projeção da vítima no campo social tornaram-se também formas de ampliação dos alcances do Estado polícia, o que pode ser uma estratégia bastante eficaz nesse sentido, haja vista que se utilizam da identificação, comoção e indignação frente ao sofrimento da pessoa agravada. Afinal, quem questionaria esta última diante de seu padecimento e dos relatos exibidos na mídia e nas votações no plenário da Câmara Federal? Qualquer objeção seria colocar em dúvida a própria vítima.

Em que pese as limitações do presente estudo no que tange ao contexto, origem e número de Projetos de Leis revisados, não se pode negar a confluência deles com notícias veiculadas pela mídia envolvendo vítimas, particularmente as de crime - de modo semelhante ao que vem ocorrendo em outros países.

Diante do exposto, constata-se que certo regime de verdade, do qual toma parte a elaboração de novas leis em (com) nome de vítimas no país, pode contribuir para a produção de formas subjetivas que se identificam com a vítima homenageada e, com isso, clamam pela proteção do Estado polícia. Esse dado aponta, ainda, para a necessidade de novos estudos que investiguem como tal identificação pode modificar o modo como os indivíduos dão sentido ao seu sofrimento, experiências e relações pessoais em um contexto histórico de exaltação das vítimas. 


\section{Referências}

Fórum Brasileiro de Segurança Pública. (2015). Anuário Brasileiro de Segurança Pública. Ano 9.

Aracatu Online. (2015). Deputado cria projeto de lei "Cristiano Araújo", que obriga instalação de detector de cinto do segurança. 25 de junho. Recuperado em 15 de dezembro de 2015, de http://www.aratuonline.com.br/noticias/apresentadoprojeto-de-lei-cristiano-araujo-que-obriga-montadoras-ainstalar-detector-de-cinto-de-seguranca/

Baratta, A. (2002). Criminologia Crítica e Crítica do Direito Penal: introdução à sociologia do direito penal. Rio de Janeiro: Revan.

Batista, N. (2011). Sobre el filo de la navaja. Revista EPOS, 2(1), 120.

Batista, N. (2007). Só Carolina Não Viu - Violência Doméstica e Políticas Criminais no Brasil. In Mello, A. R. (Org.) Comentários à Lei de Violência Doméstica e Familiar contra a Mulher ( $p$. ixxxiii). Rio de Janeiro: Editora Lumen Júris.

Bauman, Z. (2009). Vida Líquida. Rio de Janeiro: Jorge Zahar Ed.

Brasiliense, D. R. (2010). Mentes perigosas: a normatização midiatizada mora ao lado. Revista Epos, 1(2), 1-20.

Beiras, A., Moraes, M., Alencar-Rodrigues, R., \& Cantera, L. M. (2012). Políticas e leis sobre violência de gênero - reflexões críticas. Psicologia \& Sociedade, 24(1), 36-45.

Birman, J. (2005). O assédio na atualidade e seus jogos de verdade. Revista do Departamento de Psicologia - UFF, 17(1), 29-44.

Casara, R. R. R. (2015). Processo Penal do Espetáculo: ensaios sobre o poder penal, a dogmática e o autoritarismo na sociedade brasileira. Florianópolis: Empório do Direito Editora.

Cerruti, P. (2009). Procesos emocionales y respuestas punitivas: acerca del activismo penal de las víctimas del delito. Revista Electrónica de Psicología Política, Año7(20), julio/agosto, 15-25.

Coimbra, C. M. B. \& Scheinvar, E. (2012). Subjetividades punitivopenais. In Malaguti Batista, V. (Org.). Loic Wacquant e a questão penal no capitalismo neoliberal (p. 61-70). Rio de Janeiro: Revan.

Coimbra, C. M. B. \& Nascimento, M. L. (2009). Movimentos sociais e sociedade de controle. In Tedesco, S., \& Nascimento, M. L. (Orgs.). Ética e subjetividade? Novos impasses no contemporâneo (p. 39-59). Porto Alegre: Sulina.

Decat, E. (2012). Câmara define penas para crime cibernético. Folha de S. Paulo. Cotidiano, 16 de maio. Recuperado em 15 de dezembro de 2015, de: <http://www1.folha.uol.com.br/fsp/cotidiano/43201-camaradefine-penas-para-crime-cibernetico.shtml> 
Eliacheff, C., \& Larivière, D. S. (2007). Les temps des victimes. Paris: Albino Michel.

Foucault, M. (1995). A arqueologia do saber. Rio de Janeiro: Forense Universitária.

Foucault, M. (2007). Vigiar e Punir: história da violência nas prisões. Petrópolis, RJ: Vozes.

Foucault, M. (2008). Segurança, território, população: curso no Collége de France (1977-1978). São Paulo: Martins Fontes.

G1 (2012). Carolina Dieckmann fala pela $1^{\text {a }}$ vez sobre fotos e diz que espera 'justiça'. 14 de maio. Recuperado em 28 de dezembro de 2015, de: <http://g1.globo.com/poparte/noticia/2012/05/carolina-dieckmann-fala-pela-1-vezsobre-roubo-de-fotos-intimas.html>

Garland, D. (2008). A cultura do controle: crime e ordem social na sociedade contemporânea. Rio de Janeiro: Revan.

Guerreiro, G. (2014). Senado aprova 'Lei da Palmada'; texto segue para sanção de Dilma. Folha de S. Paulo. Cotidiano, 04 de junho. Recuperado em 15 de dezembro de 2015, de: <http://www1.folha.uol.com.br/cotidiano/2014/06/1465192senado-aprova-lei-da-palmada-texto-segue-para-sancao-dedilma.shtml>

Guimarães, L. (2010). Projeto proíbe pai de dar palmada e beliscão em filho. Folha de S. Paulo. Cotidiano. 14 de julho. Recuperado em 15 de dezembro de 2015, de: <http://www1.folha.uol.com.br/fsp/cotidian/ff1407201013.htm $>$

Karan, M. L. (1996). A esquerda punitiva. Revista discursos sediciosos - crime, direito e sociedade. Rio de Janeiro: RelumeDumará, no 1 , ano 1,10 semestre, 79-92.

Kehl, M. R. (2015). Ressentimento. São Paulo: Casa do Psicólogo.

Malaguti Batista, V. (2009). Adeus às ilusões "re". In Coimbra, M. C. B.; Ayres, L. S. M. \& Nascimento, M. L. (Orgs.). PIVETES: encontros entre a psicologia e o judiciário (p. 195-199). Curitiba: Juruá.

Malaguti Batista, V. (2011). O Alemão é muito mais complexo. Agência de Notícias das Favelas, 13 de set., 1-16. Recuperado em 10 de dezembro de 2015, de: <http://www.anf.org.br/2011/09/o-alemao-e-muito-maiscomplexo/>.

Martins, R. (2014). Mulher morta após ser linchada pode dar nome a lei no Congresso. G1. Santos e Região. 13 de maio. Recuperado em 15 de dezembro de 2015, de: <http://g1.globo.com/sp/santosregiao/noticia/2014/05/mulher-morta-apos-ser-linchada-podevirar-nome-de-lei-no-congresso.html> 
Montenegro, M. (2015). Lei Maria da Penha: uma análise criminológico-crítica. Rio de Janeiro: Revan.

Salas, D. (2010). La volonté de punir: essai sur le populisme penal. Paris: Pluriel.

Sousa, A. M. (2015). Bullying, assédio moral e alienação parental: a produção de novos dispositivos de controle social. Curitiba: Juruá.

Vasconcelos, A. \& Brigido, C. (2009). Crime sexual contra menores terá prazo de prescrição maior. O Globo. O País, 01 de outubro, p.1. Recuperado em 15 de dezembro de 2015, <http://acervo.oglobo.globo.com/busca/?busca=Crime+sexual +contra+menores+ter\%C3\%A $1+$ prazo+de+prescri\%C3\%A7\% C3\%A3o+maior>

Vaz. P. (2010). A vida feliz das vítimas. In J. Freire Filho (Org.), Ser feliz hoje: reflexões sobre o imperativo da felicidade (p. 135164). Rio de janeiro: Ed. FGV.

Wacquant, L. (2012). Forjando o estado neoliberal: trabalho social, regime prisional e insegurança social. In V. Malaguti Batista (Org.), Loic Wacquant e a questão penal no capitalismo neoliberal (p. 11-42). Rio de Janeiro: Revan.

\section{Endereço para correspondência \\ Analicia Martins de Sousa \\ Universidade Federal do Rio de Janeiro - UFRJ \\ Av. Pasteur, 250, Praia Vermelha, CEP 22290-240, Rio de Janeiro - RJ, Brasil \\ Endereço eletrônico: analiciams@gmail.com}

Recebido em: 28/01/2016

Reformulado em: $19 / 11 / 2016$

Aceito em: 28/03/2017

\section{Notas}

* Doutora em Psicologia Social pela Universidade do Estado do Rio de Janeiro. Bolsista de Pós-Doutorado (FAPERJ) na Escola de Comunicação da Universidade Federal do Rio de Janeiro.

${ }^{1}$ Recuperado em 15 de dezembro de 2015, de: <http://www2.camara.leg.br/>

2 Tendo em vista que no texto do PL6719/09 não consta o item "justificativa", a análise dos argumentos que embasam a proposta de lei será feita sobre o texto do Projeto de Lei do Senado 234/09, o qual deu origem aquele documento.

3 A lei de crimes hediondos, Lei 8.072 de 25 de julho 1990, foi motivada especialmente a partir dos sequestros dos empresários Roberto Medina e Abílio Diniz naquele ano. Em 1994, ela foi modificada pela Lei 8930 que inclui o homicídio no rol dos crimes hediondos. Essa lei foi criada a partir da mobilização promovida pela novelista Glória Perez em torno do assassinato da filha, a atriz Daniela Perez, em 1992.

Este artigo de revista Estudos e Pesquisas em Psicologia é licenciado sob uma Licença Creative Commons Atribuição-Não Comercial 3.0 Não Adaptada. 